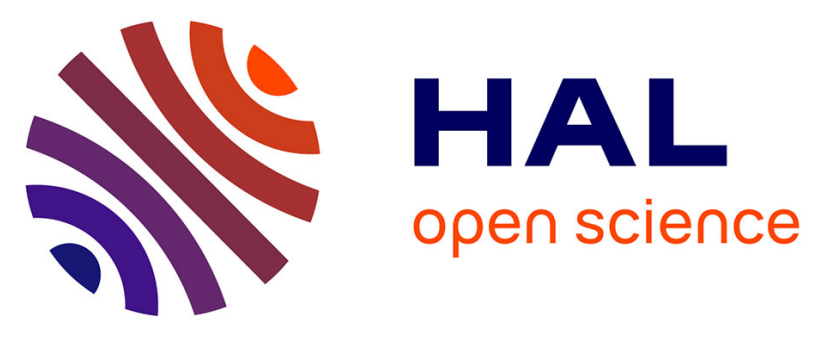

\title{
Use of the intramuscular route to administer pentamidine isethionate in Leishmania guyanensis cutaneous leishmaniasis increases the risk of treatment failure
}

Jacques-Robert Christen, Eliane Bourreau, Magalie Pierre Demar, Edward Lightburn, Pierre Couppié, Marine Ginouvès, Ghislaine Prevot, Jean-Pierre Gangneux, Helene Savini, Frank de Laval, et al.

\section{- To cite this version:}

Jacques-Robert Christen, Eliane Bourreau, Magalie Pierre Demar, Edward Lightburn, Pierre Couppié, et al.. Use of the intramuscular route to administer pentamidine isethionate in Leishmania guyanensis cutaneous leishmaniasis increases the risk of treatment failure. Travel Medicine and Infectious Disease, 2018, 24, pp.31-36. 10.1016/j.tmaid.2018.02.010 . hal-01858748

\section{HAL Id: hal-01858748 https://hal.science/hal-01858748}

Submitted on 12 Apr 2019

HAL is a multi-disciplinary open access archive for the deposit and dissemination of scientific research documents, whether they are published or not. The documents may come from teaching and research institutions in France or abroad, or from public or private research centers.
L'archive ouverte pluridisciplinaire HAL, est destinée au dépôt et à la diffusion de documents scientifiques de niveau recherche, publiés ou non, émanant des établissements d'enseignement et de recherche français ou étrangers, des laboratoires publics ou privés. 


\title{
Use of the intramuscular route to administer pentamidine isethionate in Leishmania guyanensis cutaneous leishmaniasis increases the risk of treatment failure
}

\author{
Jacques-Robert Christen $^{\mathrm{a}, *}$, Eliane Bourreau ${ }^{\mathrm{b}}$, Magalie Demar ${ }^{\mathrm{c}, \mathrm{d}}$, Edward Lightburn ${ }^{\mathrm{a}}$, \\ Pierre Couppié ${ }^{\mathrm{c}, \mathrm{e}}$, Marine Ginouvès ${ }^{\mathrm{c}}$, Ghislaine Prévot $^{\mathrm{c}}$, Jean-Pierre Gangneux ${ }^{\mathrm{f}}$, Hélène Savini ${ }^{\mathrm{a}}$, \\ Frank de Laval ${ }^{\mathrm{g}, \mathrm{h}}$, Vincent Pommier de Santi ${ }^{\mathrm{g}, \mathrm{h}, 1}$, Sébastien Briolant ${ }^{\mathrm{g}, \mathrm{i}, \mathrm{j}, 1}$

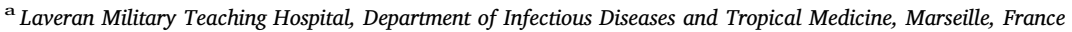 \\ ${ }^{\mathbf{b}}$ Immunology Laboratory for Leishmaniasis, Institut Pasteur in French Guiana, Cayenne, French Guiana \\ ${ }^{c}$ Amazonian Ecosystems and Tropical Pathologies-EA 3593-Labex CEBA-Department of Medicine, University of French Guiana, Cayenne, French Guiana \\ d Laboratory of Parasitology-Mycology, Andrée Rosemon Hospital, Cayenne, French Guiana \\ e Department of Dermatology, Andrée Rosemon Hospital, Cayenne, French Guiana \\ ${ }^{\mathrm{f}}$ Rennes University Hospital, Parasitology-Mycology Laboratory, Inserm U1085-Research Institute for Environmental and Occupational Health (IRSET), 35000 Rennes, \\ France \\ ${ }^{\mathrm{g}}$ French Armed Forces Medical Health Service, French Guiana, France \\ ${ }^{\mathbf{h}}$ French Armed Forces Center for Epidemiology and Public Health, Marseille, France \\ ${ }^{\mathrm{i}}$ Armed Forces Biomedical Research Institute, Brétigny-sur-Orge, France \\ j URMITE, Aix-Marseille University, UM63, CNRS 7278, IRD 198, INSERM 1095, IHU - Méditerranée Infection, Marseille, France
}

\section{A R T I C L E I N F O}

\section{Keywords:}

French Guiana

Military personnel

Leishmania guyanensis

Pentacarinat

Intravenous

\begin{abstract}
A B S T R A C T
Background: New world cutaneous leishmaniasis (NWCL) can be found in French Guiana as well as in several other parts of Central and South America. Leishmania guyanensis accounts for nearly 90\% of cases in French Guiana and is treated with pentamidine isethionate, given by either intramuscular or intravenous injection. The military population is particularly exposed due to repeated missions in the rainforest. The purpose of the present study was to identify the factors associated with pentamidine isethionate treatment failure in a series of service members with L. guyanensis NWCL acquired in French Guiana.

Method: All the French service members reported as having acquired leishmaniasis in French Guiana from December 2013 to June 2016 were included.

Results: Seventy-three patients infected with L. guyanensis were included in the final analysis. Patients treated with IV pentamidine isethionate had better response rates than those treated with IM pentamidine isethionate $(\mathrm{p}=0.002$, adjusted odds ratio $(A O R)=0.15,95 \%$ CI $[0.04-0.50])$. The rate of treatment success was $85.3 \%$ (95\% CI [68.9-95.0]) for IV pentamidine isethionate and 51.3\% (95\% CI [34.8-67.6]) for IM pentamidine isethionate.

Conclusions: The use of intramuscular pentamidine isethionate in the treatment of Leishmania guyanensis cutaneous leishmaniasis is associated with more treatment failures than intravenous pentamidine isethionate.
\end{abstract}

\section{Introduction}

Cutaneous leishmaniasis seems to be a growing concern in endemic countries [1] and among travelers [2]. New world cutaneous leishmaniasis (NWCL), also called American tegumentary leishmaniasis, is endemic in several parts of Central and South America. In French Guiana, a French overseas entity in South America located between Suriname and Brazil, five species of parasite are known to infect humans: Leishmania guyanensis, L. braziliensis, L. amazonensis, L. lainsoni, and L. naiffi [3]. L. guyanensis, a species of the Viannia subgenus, is restricted to the rainforests of Brazil, Colombia, Guyana, Suriname, and French Guiana. It is the predominant species in French Guiana, accounting for nearly $90 \%$ of cases [3,4]. It is transmitted by a sand fly vector, Lutzomyia umbratilis. The main reservoir is the two-toed sloth (Choleopus didactylus) [5].

\footnotetext{
* Corresponding author. Laveran Military Teaching Hospital, Department of Infectious Diseases and Tropical Medicine, 34, bd Laveran - CS 50004, Marseille, 13384, France.

E-mail address: jako.christen@gmail.com (J.-R. Christen).

${ }^{1}$ Dr. Pommier de Santi and Dr. Briolant contributed equally to this work.
} 
In French Guiana, the military population is particularly exposed to the parasite's life cycle during repeated missions in the rainforest to control illegal gold mining [6], and even more during training periods at the Tropical Forest Training Center (Global Positioning System decimal degrees: 4.281285, -52.157639 ), a historical focus of NWCL [7-9]. Service members are trained there for several weeks and are exposed to the sand flies through various physical activities (including tree felling), occasionally at night.

Each year, fluctuations in incidence depend on the occurrence of military activities during seasonal peaks in the parasite's life cycle, which usually occur during the first semester, and on occasional outbreaks when preventive measures are misapplied [7-10]. Since each service member diagnosed with NWCL becomes unavailable until cured, the disease can strongly impact military operational capabilities. Therefore, the French Military Health Service is looking for the most effective and simple treatment to limit the period of unavailability.

Only a few studies have addressed improvement following treatment for NWCL in French Guiana [9-11]. The reported rates of treatment success vary widely. It was $89 \%$ in a study by Nacher et al., in 2001 [12] and 58\% in a study by Neves et al., in 2011 after one round of treatment [13]. The current French treatment recommendations for L. guyanensis are to use intravenous (IV) or intramuscular (IM) pentamidine isethionate [5]. The choice of route of administration is left to the judgment of the physician. In fact, IM treatment is chosen in a large majority of cases [14]. In French Guiana, the habitual procedure is to use IM treatment because the most exposed populations in the forest are migrants, illegal gold miners who are usually poorly compliant and can be reluctant to be hospitalized. The IV route of administration for pentamidine isethionate is the preferred one in the United States and Canada according to the recent Infectious Diseases Society of America and American Society of Tropical Medicine and Hygiene guidelines, but without any study to support this choice [15]. Thus, evidence about the effect of the route of pentamidine isethionate administration on the treatment of NWCL due to L. guyanensis is needed.

Several factors are associated with treatment failure: geographic distribution [15], Leishmania species [15,16], meteorological parameters [17], dissemination [12], higher number of lesions [14,18], younger age [18], early or delayed treatment $[18,19]$, shorter duration of exposure in an endemic region [18], intralesional interleukin-10 and Foxp3 mRNA expression [20], and HIV co-infection [21]. Some of these factors may appear paradoxical and could account for a poor immune response [22].

In addition, Leishmania guyanensis, L. braziliensis, L. amazonensis, and L. lainsoni can be infected by a virus belonging to the Totiviridae family: Leishmania RNA virus type 1 (LRV). It was discovered in 1988 in a sample originally isolated from a visitor to Suriname [23]. The presence of this virus in the parasites seems to influence the cure rate $[14,18,24,25]$. The infected parasites tend to spread, and Bourreau et al. have shown that the presence of the virus increases the risk of treatment failure and relapse [14].

The purpose of the present study was to identify the factors associated with pentamidine isethionate treatment failure in a series of service members with $L$. guyanensis NWCL acquired in French Guiana.

\section{Methods}

\subsection{Study design}

This study is a case series. Diagnostic samples and treatment were performed in the context of routine care. Data were then collected with patient consent. The end-point was defined as patient recovery, confirmed by the epithelialization of the lesion, measured six weeks after the beginning of treatment.

\subsection{Diagnosis and case definition}

A complete diagnostic strategy was used for all patients in French Guiana: direct smear examination and two intra-lesional punch biopsies for species diagnosis (culture, PCR) and LRV diagnosis by quantitative reverse transcription-PCR [14]. A restriction fragment length polymorphism-PCR analysis was performed on parasite cultures for the patients treated in French Guiana [4,11]. For the patients diagnosed in continental France after returning from French Guiana, various methods were used [26].

A leishmaniasis case was defined as any cutaneous lesion associated with confirmed parasitological evidence (Leishmania spp. in direct smear examination, culture, or polymerase chain reaction (PCR)) contracted in French Guiana.

\subsection{Treatment strategy}

The treatment was left to the appreciation of the physician taking care of the patient, either a general practitioner or a hospital specialist. The L. guyanensis-infected patients were included in the final analysis; they were treated by pentamidine isethionate (Pentacarinat, SanofiAventis), either IV or IM. A bottle of Pentacarinat contains $300 \mathrm{mg}$ of pentamidine diisethionate (171 $\mathrm{mg}$ of pentamidine). Treatment with intravenous pentamidine isethionate consisted of one injection of $4 \mathrm{mg}$ / $\mathrm{kg}$ repeated every $48 \mathrm{~h}$ for a total of three times. The IM pentamidine isethionate was administered in two injections given on a single day in two different sites at the same time for a total of $7 \mathrm{mg} / \mathrm{kg}$.

All patients attended a follow-up visit six weeks after the onset of the treatment.

Treatment failure was defined as the persistence of the lesion without improvement six weeks after treatment, which led to a second treatment.

\subsection{Data collection}

Cases were reported to the French armed forces epidemiological surveillance system in French Guiana (autochthonous cases) and in continental France (imported cases).

All the French service members reported to have had leishmaniasis in French Guiana or on returning from French Guiana from December 2013 to June 2016 were included.

Physicians were called to collect data about species, presence of LRV, treatment strategy, and follow-up. Suspected area of contamination, number of lesions, dissemination-defined as secondary lesions surrounding the initial lesion or a certain distance from it-, diameter, time between diagnosis and treatment, and side effects were recorded.

Only L. guyanensis-infected patients with a complete follow-up were included in the final analysis. Those infected with another species were included for epidemiological purposes.

\subsection{Statistical analysis}

Statistical analyses were done using SAS University ${ }^{\circledR}$ software (SAS Institute Inc., NC, USA). Given the small sample sizes, the Fisher exact test was used for univariate analysis. Logistic regression was used for multivariate analysis. All statistical analyses used a 5\% significance level. The following variables were included in the analyses: age, number of lesions, diameter of lesions, dissemination, stays at goldmining site, presence of LRV, time between diagnosis and treatment and route of administration of treatment.

\section{Results}

Ninety-seven patients were included (Fig. 1), 50 in French Guiana and 47 in continental France. Five were included in 2013, 53 in 2014, 22 in 2015, and 17 in 2016. 


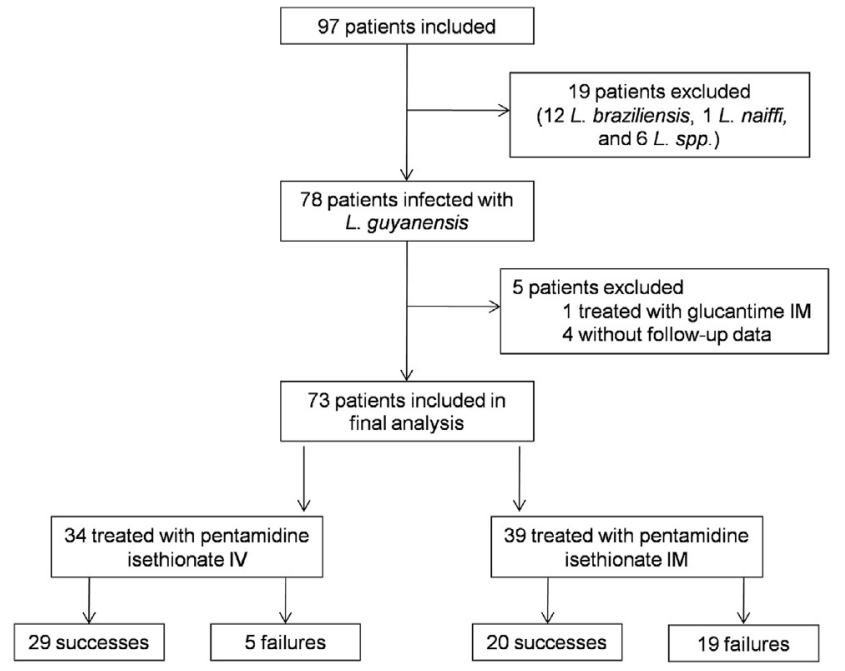

Fig. 1. Flowchart.

Among the 91 patients for whom species identification was available, 78 (86\%) were infected with $L$. guyanensis, 12 (13\%) with $L$. braziliensis, and 1 (1\%) with $L$. naiffi.

The suspected areas of contamination are shown in Fig. 2. The main area of contamination, with 46 cases, was Régina, where the Tropical Forest Training Center is located. The cases due to L. braziliensis were mainly distributed at the gold mining sites around Dorlin, Eau-Claire, and Saül.

Seventy-three patients infected with L. guyanensis were included in the final analysis (Fig. 1). The characteristics of the patients are presented in Table 1 . Their median age was 28 years (Inter-quartile interval (IQI) [23-33], minimum (min) 21, maximum (max) 44). All the patients except one were men. The median number of lesions was one (IQI [1.0-1.0], min 1.0, $\max 4.0$ ). The prevalence of LRV was $84.8 \%$

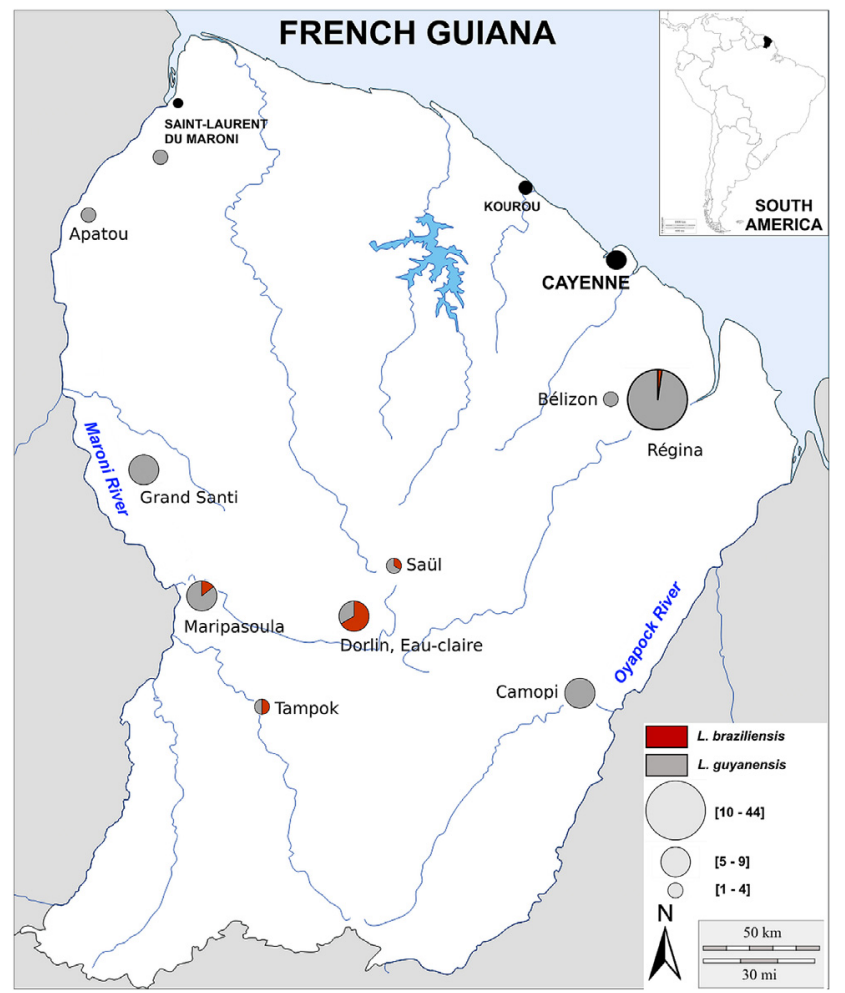

Fig. 2. Map of French Guiana with suspected areas of contamination ( $N=79$ with location reported).
Table 1

Characteristics of patients with American tegumentary leishmaniasis due to Leishmania guyanensis parasites treated with pentamidine isethionate $(\mathrm{N}=73)$.

\begin{tabular}{|c|c|}
\hline Characteristics & $\mathrm{n}(\%)$ \\
\hline \multicolumn{2}{|l|}{ Sex } \\
\hline Male & $72(98.6)$ \\
\hline Female & $1(1.4)$ \\
\hline \multicolumn{2}{|l|}{ Age (years) } \\
\hline$\leq 25$ & 24 (32.9) \\
\hline$>25$ & $49(67.1)$ \\
\hline \multicolumn{2}{|l|}{ Number of lesions } \\
\hline 1 & $59(80.8)$ \\
\hline 2 & $9(12.3)$ \\
\hline 3 & $4(5.5)$ \\
\hline 4 & $1(1.4)$ \\
\hline \multicolumn{2}{|l|}{ Diameter of lesions (mm) } \\
\hline$\leq 10$ & $24(37.5)$ \\
\hline$>10$ & $40(62.5)$ \\
\hline Dissemination & $33(45.8)$ \\
\hline \multicolumn{2}{|l|}{ Area of contamination } \\
\hline Training Center & $41(56.2)$ \\
\hline Other forested areas & $32(43.8)$ \\
\hline Presence of Leishmania RNA virus 1 & $50(84.8)$ \\
\hline \multicolumn{2}{|c|}{ Time between diagnosis and treatment (days) } \\
\hline$\leq 40$ & $37(50.7)$ \\
\hline$>40$ & $36(49.3)$ \\
\hline \multicolumn{2}{|l|}{ Route of administration } \\
\hline IM & $39(53.4)$ \\
\hline IV & $34(46.6)$ \\
\hline \multicolumn{2}{|l|}{ Side effects } \\
\hline IM & $9(23.1)$ \\
\hline IV & $12(35.3)$ \\
\hline
\end{tabular}

$(\mathrm{n}=50)$. The median time between diagnosis and treatment was 40 days (IQI [27-57], min 5, max 1148).

Time less than 40 days between diagnosis and treatment was significantly associated with treatment failure in univariate analyses but not in multivariate analyses. The route of administration was the only factor significantly associated with treatment failure in univariate and multivariate analyses (Table 2). The dissemination variable was forced into the multivariate analysis because it had been previously described as a risk factor of therapeutic failure [12]. Patients treated with IV pentamidine isethionate had better response rates than those treated with IM pentamidine isethionate $(\mathrm{p}=0.002$, adjusted odds ratio $(A O R)=0.15,95 \%$ CI $[0.04-0.50])$. The treatment success rate was 85.3\% (95\% CI [68.9-95.0]) for IV pentamidine isethionate and 51.3\% (95\% CI [34.8-67.6]) for IM pentamidine isethionate. The overall success rate was $67.1 \%$ (95\% CI [55.1-77.7]).

No association was found between treatment failure and age, suspected area of contamination, number of lesions, diameter of lesions, and dissemination. The presence of LRV was not associated with treatment failure, an increased number of lesions, a greater diameter, the suspected area of contamination, or dissemination (Table 3).

For the IM treatment, several known side effects were recorded: asthenia (2/39), pain (1/39), myalgia (1/39), rhabdomyolysis $(3 / 39)$, dysesthesia (1/39), and low blood pressure (1/39). Known side effects were also recorded for the IV treatment: asthenia $(2 / 34)$, pain $(1 / 34)$, hypoglycemia (2/34), abdominal pain (1/34), myalgia (1/34), arthralgia $(1 / 34)$, veinitis $(1 / 34)$, facial edema $(1 / 34)$, flushing $(1 / 34)$, eosinophilia (1/34), electrocardiogram modification $(1 / 34)$, and dyspepsia (1/34). After a failure, second-line treatments reported were: meglumine antimoniate (Glucantime) local $(n=1)$ and IM $(n=4)$; IV 
Table 2

Determinants of pentamidine isethionate treatment failure in patients with L. guyanensis cutaneous leishmaniasis in French Guiana.

\begin{tabular}{|c|c|c|c|c|c|c|c|c|c|}
\hline & \multirow[t]{2}{*}{$\mathrm{N}$} & \multirow[t]{2}{*}{$\mathrm{n}$} & \multirow[t]{2}{*}{$\%$} & \multicolumn{3}{|c|}{ Univariate analysis } & \multicolumn{3}{|c|}{ Multivariate analysis } \\
\hline & & & & COR & $95 \% \mathrm{CI}$ & p-value & AOR & $95 \% \mathrm{CI}$ & p-value \\
\hline \multicolumn{10}{|c|}{ Age (years) } \\
\hline$\leq 25$ & 24 & 6 & 25.0 & 1.00 & & & & & \\
\hline$>25$ & 49 & 18 & 36.7 & 1.74 & $0.58-5.19$ & 0.3189 & & & \\
\hline \multicolumn{10}{|c|}{ Number of lesions } \\
\hline 1 & 58 & 19 & 32.8 & 1.00 & & & & & \\
\hline$>1$ & 15 & 5 & 33.3 & 0.80 & $0.28-2.31$ & 0.9663 & & & \\
\hline \multicolumn{10}{|c|}{ Diameter of lesions (mm) } \\
\hline$\leq 10$ & 24 & 9 & 37.5 & 1.00 & & & & & \\
\hline$>10$ & 40 & 13 & 32.5 & 0.80 & $0.28-2.31$ & 0.6840 & & & \\
\hline \multicolumn{10}{|c|}{ Dissemination } \\
\hline No & 40 & 12 & 30.0 & 1.00 & & & 1.00 & & \\
\hline Yes & 33 & 12 & 36.4 & 1.33 & $0.50-3.55$ & 0.5650 & 2.10 & $0.69-6.44$ & 0.1929 \\
\hline \multicolumn{10}{|c|}{ Travel to gold mining site } \\
\hline No & 44 & 13 & 29.5 & 1.00 & & & & & \\
\hline Yes & 25 & 11 & 44.0 & 1.87 & $0.67-5.20$ & 0.2282 & & & \\
\hline \multicolumn{10}{|c|}{ Presence of Leishmania RNA virus 1} \\
\hline No & 9 & 2 & 22.2 & 1.00 & & & & & \\
\hline Yes & 50 & 17 & 34.0 & 1.80 & $0.34-9.65$ & 0.4910 & & & \\
\hline \multicolumn{10}{|c|}{ Time between diagnosis and treatment (days) } \\
\hline$\leq 40$ & 37 & 17 & 45.9 & 1.00 & & & & & \\
\hline$>40$ & 36 & 7 & 19.4 & 0.28 & $0.10-0.81$ & 0.0186 & & & \\
\hline \multicolumn{10}{|c|}{ Route of administration } \\
\hline IM & 39 & 19 & 48.7 & 1.00 & & & 1.00 & & \\
\hline IV & 34 & 5 & 14.7 & 0.18 & $0.06-0.57$ & 0.0033 & 0.15 & $0.04-0.50$ & 0.0020 \\
\hline
\end{tabular}

$\mathrm{n}$ : number of patients with therapeutic failure.

95\% CI: 95\% confidence interval.

COR: crude odds ratio; AOR: adjusted odds ratio.

Table 3

Influence of the presence of Leishmania RNA virus 1 (LRV) on clinical presentation (univariate analysis) ( $n=58$ tested for LRV).

\begin{tabular}{|c|c|c|c|}
\hline Characteristic & Presence of LRV n (\%) & Absence of LRV n (\%) & p-value \\
\hline \multicolumn{4}{|c|}{ Number of lesions } \\
\hline 1 & $42(84)$ & $8(88.9)$ & 0.2991 \\
\hline 2 & $6(12)$ & $1(11.1)$ & \\
\hline 3 & $1(2)$ & $0(0)$ & \\
\hline 4 & $1(2)$ & $0(0)$ & \\
\hline \multicolumn{4}{|c|}{ Diameter of lesions (mm) } \\
\hline$\leq 10$ & $17(39.5)$ & $4(50)$ & 0.2576 \\
\hline$>10$ & $26(60.5)$ & $4(50)$ & \\
\hline Dissemination & $19(38.8)$ & $6(66.7)$ & 0.0907 \\
\hline
\end{tabular}

$(\mathrm{n}=2)$, liposomal amphotericin B IV $(\mathrm{n}=2)$; and pentamidine isethionate local $(n=1)$, IM $(n=6)$ and IV $(n=15)$.

\section{Discussion}

The present study shows that use of the IM route of administration for pentamidine isethionate in the treatment of Leishmania guyanensis cutaneous leishmaniasis was associated with more treatment failures at six weeks. The advantage of the IV strategy for the patient is obvious, as it led to a faster cure, of particular importance for a disease that can be an esthetic challenge. It is also beneficial for military forces, since it enables them to be maintained in a better operational condition: Service members with cutaneous leishmaniasis are forbidden from going into the rainforest until cured and cannot carry out their missions during this time. Moreover, the IM route of administration is more painful, due to the occurrence of rhabdomyolysis, a side effect absent with IV administration [27,28]. However, IV infusion can cause anaphylactic shock on rare occasions, making medical surveillance following infusion mandatory $[29,30]$. This side effect has never been reported with IM pentamidine.
The overall treatment success rate in our study was lower than rates reported in the literature [12,31,32]. The success rate for IM pentamidine isethionate was similar to that observed in the study by Neves et al. [13]. The decreased efficacy of the IM pentamidine isethionate observed in other studies could be reversed by the use of the IV [33]; a possible explanation is that the serum peak of pentamidine is higher with this route of administration.

None of the previously described risk factors for poor response to treatment were found in our study. In particular, we found no association between treatment failure and the presence of LRV, unlike Bourreau et al. [14]. Even if it may seem puzzling at first, this difference can easily be explained, we defined treatment failure as unresponsiveness to one course of treatment, whereas Bourreau et al. defined it as unresponsiveness to two courses. In 2005, in a study about French service members contaminated in French Guiana who experienced treatment failure, the patients $(n=7)$ were cured with a regimen of four intravenous injections of pentamidine [34]. Moreover, the host's immune system was not studied, and as the populations included in our study and in Bourreau et al. were different, an influence of this factor cannot be excluded. Another explanation is that our study may have lacked the statistical power to show an influence of LRV.

A greater time between diagnosis and treatment is associated with less treatment failure in univariate analysis but not in multivariate analysis. This is explained by its collinearity with the route of administration. We can assume that more patients with a greater time between diagnosis and treatment were treated in continental France, where the use of IV pentamidine isethionate is more common.

Our study also constitutes an update on the epidemiology of leishmaniasis in French Guiana. Leishmania guyanensis accounts for $86 \%$ of the cases there, a similar proportion to that found in the literature $[3,4,35]$. Due to missions carried out in the rainforest, service members are exposed to the same parasites as illegal gold miners. The distribution of the cases was interesting. The cases due to Leishmania braziliensis were distributed at the gold mining sites around Dorlin, Eau-Claire, and Saïl and the parasite may have been introduced in French Guiana by individuals entering illegally from Brazil for gold mining. The Tropical 
Forest Training Center in Régina is a historical focus of cutaneous leishmaniasis in French Guiana as far as service members are concerned. It was therefore not surprising that most of the contamination took place there. Compared to the map in the study by Ginouvès et al. [36], the areas of contamination in our study were restricted to the places where service members were located or traveled for missions or training. Thus, fewer areas of contamination were represented. Nevertheless, the main focus is Régina in the two studies, and the general findings relating to the distribution of cases are similar.

The limitations of our study are mainly due to its design. A randomized, controlled, blind trial would have a higher level of evidence. We had several patients lost to follow-up, all of whom were treated with IV pentamidine isethionate. Even though declaration of cutaneous leishmaniasis is mandatory and French military physicians are disciplined, some patients may not have been reported during the time period of the study. However, it is unlikely that diagnosis was missed, since all service members receive information about the local health hazards before shipping out to French Guiana, and cutaneous leishmaniasis is given considerable prominence. Our population is a specific one and is not representative of the general population exposed to NWCL, in particular because only service members in good health can be sent overseas, which can change the host response to the parasite. Another limitation is that our study was restricted to French Guiana and the results cannot be extrapolated to other places, as it is known that geographic location can influence treatment response [15].

In summary, the use of IM pentamidine isethionate administered on a single day in the treatment of Leishmania guyanensis cutaneous leishmaniasis is associated with more treatment failures than IV pentamidine isethionate. According to our data, IV pentamidine isethionate should be the preferred treatment for Leishmania guyanensis cutaneous leishmaniasis, with the IM route of administration being reserved for situations where IV infusion and medical surveillance are not available or possible. Confirmatory studies, especially in other countries, are necessary. It could also be worthwhile to conduct another study on the IM protocol consisting of two injections given in two different sites for a total of $7 \mathrm{mg} / \mathrm{kg}$ of pentamidine isethionate repeated once after $48 \mathrm{~h}$.

\section{Funding}

This work was supported by the French Military Health Service. The funders had no role in study design, data collection and analysis, decision to publish, or preparation of the manuscript.

\section{Conflicts of interest}

The authors declare that there are no conflicts of interest.

\section{Acknowledgments}

The opinions or assertions expressed here are the personal views of the authors and should not be considered official or as a reflection of the views of the French Military Health Service.

\section{References}

[1] Karimkhani C, Wanga V, Coffeng LE, Naghavi P, Dellavalle RP, Naghavi M. Global burden of cutaneous leishmaniasis: a cross-sectional analysis from the Global Burden of Disease Study 2013. Lancet Infect Dis 2016;16:584-91.

[2] Schwartz E, Hatz C, Blum J. New world cutaneous leishmaniasis in travellers. Lancet Infect Dis 2006;6:342-9.

[3] Dedet J-P, Carme B, Desbois N, Bourdoiseau G, Lachaud L, Pratlong F. Epidemiology of autochthonous leishmaniasis in France. Presse Med 2013;42:1469-81.

[4] Simon S, Nacher M, Carme B, Basurko C, Roger A, Adenis A, et al. Cutaneous leishmaniasis in French Guiana: revising epidemiology with PCR-RFLP. Trop Med Health 2017;45:5.

[5] Buffet PA, Rosenthal É, Gangneux J-P, Lightburne E, Couppié P, Morizot G, et al. Therapy of leishmaniasis in France: consensus on proposed guidelines. Presse Med 2011;40:173-84.

[6] Rotureau B, Joubert M, Clyti E, Djossou F, Carme B. Leishmaniasis among gold miners, French Guiana. Emerg Infect Dis 2006;12:1169-70.

[7] Berger F, Romary P, Brachet D, Rapp C, Imbert P, Garrabé E, et al. Outbreak of cutaneous leishmaniasis in military population coming back from French Guiana. Rev Epidemiol Sante Publique 2006;54:213-21.

[8] Banzet S. Epidemics of cutaneous leishmaniasis in military personnel working in French Guiana. Med Trop 2000;60:297-302.

[9] Lightburn E, Meynard JB, Morand JJ, Garnotel E, Kraemer P, Hovette P, et al Epidemiologic surveillance of cutaneous leishmaniasis in Guiana. Summary of military data collected over 10 years. Med Trop 2002;62:545-53.

[10] Nacher M, Carme B, Sainte Marie D, Couppié P, Clyti E, Guibert P, et al. Seasonal fluctuations of incubation, healing delays, and clinical presentation of cutaneous leishmaniasis in French Guiana. J Parasitol 2001;87:1495-8.

[11] Simon S, Veron V, Carme B. Leishmania spp. identification by polymerase chain reaction-restriction fragment length polymorphism analysis and its applications in French Guiana. Diagn Microbiol Infect Dis 2010;66(2):175-80.

[12] Nacher M, Carme B, Sainte Marie D, Couppié P, Clyti E, Guibert P, et al. Influence of clinical presentation on the efficacy of a short course of pentamidine in the treatment of cutaneous leishmaniasis in French Guiana. Ann Trop Med Parasitol 2001;95:331-6.

[13] Neves LO, Talhari AC, Gadelha EP, Silva Júnior RM, Guerra JA, Ferreira LC, et al. A randomized clinical trial comparing meglumine antimoniate, pentamidine and amphotericin B for the treatment of cutaneous leishmaniasis by Leishmania guyanensis. An Bras Dermatol 2011;86:1092-101.

[14] Bourreau E, Ginouves M, Prévot G, Hartley MA, Gangneux JP, Robert-Gangneux F, et al. Presence of Leishmania RNA Virus 1 in Leishmania guyanensis increases the risk of first-line treatment failure and symptomatic relapse. J Infect Dis 2016;213:105-11.

[15] Aronson N, Herwaldt BL, Libman M, Pearson R, Lopez-Velez R, Weina P, et al. Diagnosis and treatment of leishmaniasis: clinical practice guidelines by the infectious diseases society of America (IDSA) and the american society of tropical medicine and Hygiene (ASTMH). Clin Infect Dis 2016;63:1539-57.

[16] Romero GA, Guerra MV, Paes MG, Macêdo VO. Comparison of cutaneous leishmaniasis due to Leishmania (Viannia) braziliensis and L. (V.) guyanensis in Brazil: therapeutic response to meglumine antimoniate. Am J Trop Med Hyg 2001;65:456-65.

[17] Nacher M, Couppié P, Carme B, Clyti E, Sainte Marie D, Guibert P, et al. Influence of meteorological parameters on the clinical presentation of cutaneous leishmaniasis in French Guiana and on the efficacy of pentamidine treatment of the disease. Ann Trop Med Parasitol 2002;96:773-80.

[18] Adaui V, Lye L-F, Akopyants NS, Zimic M, Llanos-Cuentas A, Garcia L, et al. Association of the endobiont double-stranded RNA Virus LRV1 with treatment failure for human leishmaniasis caused by Leishmania braziliensis in Peru and Bolivia. J Infect Dis 2016;213:112-21.

[19] Machado P, Araújo C, Da Silva AT, Almeida RP, D'Oliveira Jr. A, Bittencourt A, et al. Failure of early treatment of cutaneous leishmaniasis in preventing the development of an ulcer. Clin Infect Dis 2002;34:E69-73.

[20] Bourreau E, Ronet C, Darsissac E, Lise M-C, Marie DS, Clity E, et al. In leishmaniasis due to Leishmania guyanensis infection, distinct intralesional interleukin-10 and Foxp3 mRNA expression are associated with unresponsiveness to treatment. J Infect Dis 2009;199:576-9.

[21] Couppié P, Clyti E, Sobesky M, Bissuel F, Del Giudice P, Sainte-Marie D, et al. Comparative study of cutaneous leishmaniasis in human immunodeficiency virus (HIV)-infected patients and non-HIV-infected patients in French Guiana. Br J Dermatol 2004;151:1165-71.

[22] Llanos-Cuentas A, Tulliano G, Araujo-Castillo R, Miranda-Verastegui C, SantamariaCastrellon G, Ramirez L, et al. Clinical and parasite species risk factors for pentavalent antimonial treatment failure in cutaneous leishmaniasis in Peru. Clin Infect Dis 2008;46:223-31.

[23] Tarr PI, Aline RF, Smiley BL, Scholler J, Keithly J, Stuart K. LR1: a candidate RNA virus of Leishmania. Proc Natl Acad Sci U S A 1988;85:9572-5.

[24] Ives A, Ronet C, Prevel F, Ruzzante G, Fuertes-Marraco S, Schutz F, et al. Leishmanid RNA virus controls the severity of mucocutaneous leishmaniasis. Science 2011;331:775-8.

[25] Hartley M-A, Ronet C, Zangger H, Beverley SM, Fasel N. Leishmania RNA virus: when the host pays the toll. Front Cell Infect Microbiol 2012;2:99.

[26] Van der Auwera G, Bart A, Chicharro C, Cortes S, Davidsson L, Di Muccio T, et al Comparison of Leishmania typing results obtained from 16 European clinical laboratories in 2014. Euro Surveill 2016:21.

[27] Delobel P, Pradinaud R. Rhabdomyolysis associated with pentamidine isethionate therapy for American cutaneous leishmaniasis. J Antimicrob Chemother 2003;51:1319-20.

[28] Lieber-Mbomeyo A, Lipsker D, Miléa M, Heid E. Rhabdomyolysis induced by pentamidine (Pentacarinat) during treatment of cutaneous leishmaniasis: 2 cases. Ann Dermatol Venereol 2002;129:50-2.

[29] Levy ER, Musick L, Zinter MS, Lang T, Cowan MJ, Weintrub PS, et al. Safe and effective prophylaxis with bimonthly intravenous pentamidine in the pediatric hematopoietic stem cell transplant population. Pediatr Infect Dis J 2016;35:135-41.

[30] DeMasi JM, Cox JA, Leonard D, Koh AY, Aquino VM. Intravenous pentamidine is safe and effective as primary pneumocystis pneumonia prophylaxis in children and adolescents undergoing hematopoietic stem cell transplantation. Pediatr Infect Dis J 2013;32:933-6.

[31] Roussel M, Nacher M, Frémont G, Rotureau B, Clyti E, Sainte-Marie D, et al. Comparison between one and two injections of pentamidine isethionate, at $7 \mathrm{mg} / \mathrm{kg}$ in each injection, in the treatment of cutaneous leishmaniasis in French Guiana. Ann Trop Med Parasitol 2006;100:307-14.

[32] Lightburn E, Morand JJ, Meynard JB, Kraemer P, Chaudier B, Pages F, et al 
Management of American cutaneous leishmaniasis. Outcome apropos of 326 cases treated with high-dose pentamidine isethionate. Med Trop 2003;63:35-44.

[33] van der Meide WF, Sabajo LO, Jensema AJ, Peekel I, Faber WR, Schallig HD, et al. Evaluation of treatment with pentamidine for cutaneous leishmaniasis in Suriname. Int J Dermatol 2009;48:52-8.

[34] Gangneux JP, Sauzet S, Donnard S, Meyer N, Cornillet A, Pratlong F, et al.
Recurrent American cutaneous leishmaniasis. Emerg Infect Dis 2007;13:1436-8.

[35] Desjeux P, Dedet JP. Isoenzyme characterization of 112 Leishmania isolates from French Guiana. Trans R Soc Trop Med Hyg 1989;83:610-2.

[36] Ginouvès M, Simon S, Bourreau E, Lacoste V, Ronet C, Couppié P, et al. Prevalence and distribution of Leishmania RNA virus 1 in Leishmania parasites from French Guiana. Am J Trop Med Hyg 2016;94:102-6. 